\title{
An Econometric Look at Inefficiency Among U.S. States, 1977-1986
}

Gregory Brock*

\begin{abstract}
U.S. states during the 1977-1986 business cycle are found to have small but significant technical inefficiency in the private sector. Inefficiency is influenced by several factors, including prior economic performance, location, Hicks labor augmenting technical progress in the manufacturing sector in an earlier 1970s period, college graduation, and income inequality. The existence of a monetary channel, urban agglomeration, and a high school diploma "sheepskin" effect for improved technical efficiency are rejected. Results from earlier studies using noneconometric methods to measure technical efficiency are independently confirmed, indicating that interstate technical inefficiency exists and can be measured using both parametric and nonparametric methods, but may overestimate how different states are from each other.
\end{abstract}

\section{INTRODUCTION}

Economic growth has been studied in many countries and over many time periods. However, often the subnational regions of a country and how they grow is not well understood or is assumed to be similar to the country overall. U.S. states are no exception, with very few studies of the overall aggregate economic growth of each state having been done. While the performance of U.S. states has been analyzed at several levels of aggregation, the application of a state-by-state production function at the most aggregate level using Gross State Product (GSP) to measure the entire state's economy is relatively new (Domazlicky and Weber 1998). Such analysis can examine the public/private sector influence on a state's economic growth, as well as lead to the discovery of new factors that influence a state's growth. Results from previous work that focused only on manufacturing (e.g., Williams and Moomaw 1989), banking (Carlino and DeFina 1998), and personal income (Levernier, Rickman, and Partridge 1995) can be directly incorporated into the analysis to examine those factors' influence on overall state performance. While incorporating previous research can be difficult technically, the literature on interstate performance has been inconclusive in part because independent studies are not compared with each other (Gerking 1994; Crain and Lee 1999). The purpose of this paper is to address this gap in the literature by using other interstate studies and their data with a new method to shed new light on economic growth in U.S. states during the period 1977-1986.

Recent work on overall state performance has applied a linear programming (LP) method from the stochastic frontier literature to rank states by how well they utilized existing resources to create GSP. The LP method is an input/output

*Department of Finance and Economics, Georgia Southern University, Statesboro, GA. The author would like to thank Bill Weber and Bill Levernier for providing data used in earlier work. 
method that can be parametric or nonparametric. The LP method constructs an efficient envelope or frontier using input data with standard linear programming and then compares the actual output of each unit (here, GSP for each state) to the frontier. Any unit located below the frontier is technically inefficient. When examining production, the LP method is essentially using a production function without an error term (parametric) or with neither a specific functional form nor an error term (nonparametric). Since the theoretically efficient frontier is unknown, the frontier used in empirical applications is often called the "best practice" frontier, as it is formed by those states that best utilize their inputs to produce GSP within the sample. A large literature, often found under the label "data envelopment analysis," or DEA, exists and uses the LP method to study many settings and countries (Fried, Knox Lovell, and Schmidt 1993).

In their initial examination, using an aggregate state-level nonparametric LP production function, Domazlicky and Weber (1998) explain GSP growth by both technological progress, using a trend term (shifting of a production frontier), and a state's ability to reach a given production frontier (technical efficiency). As there is no error term, there is no assumption of an error distribution, which is controversial in the literature. LP users believe that imposing an error term or even a specific functional form on an input/output relationship with little guidance from economic theory is incorrect. Critics of the LP method note that by using a deterministic method without an error term, all measurement error is assumed to be technical inefficiency and is subsumed into the state performance rankings, leading to unlikely conclusions such as states' exhibiting technological regress (Domazlicky and Weber 1997, 1999). Further, LP critics note that different functional forms can be tried and statistically tested, so the imposition of a functional form (parametric approach) is not overly restrictive. As both econometric (with an error term) and LP methods are extensively used and a theory on which error distribution best models technical inefficiency does not exist, there is no consensus in the literature on which method is better. The choice of the method used is really based on the philosophical belief of the researcher concerning which method is best (Forsund, Lovell, and Schmidt 1980). Rather than resolving the debate, the literature has moved towards using the results from both methods simultaneously. While cardinal results may differ across methods, ordinal results should be robust to choice of method if what is actually being measured is the underlying interstate technical inefficiency.

Section two briefly discusses the production function data used in previous studies plus the results and data from earlier work that are to be incorporated in the analysis. Section three outlines the econometric method and how noneconometric results compare. Section four discusses the results and Section five concludes.

\section{PREVIOUS WORK AND DATA}

Previous research on interstate performance has been inconclusive in part because of differing data sets and methods (Gerking 1994; Crain and Lee 1999). To 
avoid such criticism, data are taken directly from previous research and include comparisons with previous results that apply a production function across states. Specifically, production function aggregate state input/output data are from Domazlicky and Weber (1998), who analyze the single business cycle 1977-1986 for the 48 contiguous states. A state's aggregate output is measured by the value of GSP in 1982 dollars, with separate public and private sector series available from the Bureau of Economic Analysis. Aggregate labor $(\mathrm{L})$ is from public and private employment series from the U.S. Department of Labor's Handbook of Labor Statistics. Aggregate capital stock (K) in 1982 dollars, with separate private and public sector components, was carefully compiled by two separate authors (HoltzEakin 1993 and Munnell 1990) and has been applied since then (e.g., Crain and Lee 1999). Only 1977-1986 capital stock data are available, which limits any study of interstate production functions. One result will be simply to compare the Domazlicky and Weber (1998) LP technical efficiency rankings with the econometric rankings using the same data.

Data on variables that are believed to influence technical efficiency during the 1977-1986 period come from several previous studies. One hypothesis is that a state's economic performance will be in part determined by geographical location. History and, therefore, geography matter, as work by Krugman (1991) attempts to show theoretically. Regional dummies are used, based on a Census division of the 48 states into Northeast (NE), North Central (NC), South Atlantic (SA), South Central (SC), and West (W) regions, with the Northeast as the omitted region. The groups also are used to test for a "snowbelt" (North Central and Northeast only) versus "sunbelt" (rest of regions) effect (Williams and Moomaw 1989) on technical inefficiency. Another dummy (D82) is included to examine the impact of the short-term 1982 recession within the 1977-1986 business cycle.

A second hypothesis is that capital and/or labor augmenting (KEFF, LEFF) technical progress in the manufacturing sector of a state's economy will improve aggregate state economic performance with a lag. KEFF and LEFF are the capital and labor efficiency growth rates found in a previous study. They measure input augmenting technical progress or the more efficient use of an existing input regardless of whether the amount of the input is growing. The augmenting of capital and labor can be seen as a qualitative improvement in the use of two inputs that positively impacts output growth separately from growth in the quantity of inputs. Many studies ignore such efficiency or assume that it is not changing. Williams and Moomaw (1989) note this gap in the literature and test for input augmenting technical progress. They find the rapid growth of both the quantity of the capital input and the technological age of the capital input in the South and West during 1954-1972 boosted a state's GSP in the manufacturing component. The specific hypothesis tested here will be that the capital and labor augmenting technical progress in manufacturing they found carries over to the next business cycle (1977-1986) to impact on a state's ability to grow in general. An additional variable, equal to the percentage of a state's 1970 nonagricultural employment 
accounted for by manufacturing employment, is included to test directly for a "presence of manufacturing" (MANUSH) effect (Carlino and DeFina 1998). As non-neutral technological progress during 1977-1986 appears to vary between capital and labor saving progress, the impact of concurrent change in manufacturing KEFF and LEFF is left for future research (e.g., Domazlicky and Weber 1999) and as yet unavailable aggregate state capital stock data.

A third hypothesis is that a credit channel influences economic performance at the state level. While the idea of a regional credit channel impact of monetary policy has been proposed (Kashyap and Stein 1994) and rejected empirically (Carlino and DeFina 1998), the small bank lending data provided in the latter source can be used to test whether a large share of lending coming from small banks (BANK) influences technical inefficiency of a state over time. The hypothesis needs to be tested repeatedly, as the negative result for a regional credit channel contradicts the findings in earlier work that banking is positively related to economic growth in general (e.g. Levine and Zervos 1998). The data are the average percentage share of total loans made by a given state's small banks over the period 1976-1992. A small bank is one that is at or below the 90th percentile in terms of total assets compared with all banks across the nation. If either a positive or negative influence is found on the ability of a state to attain the efficiency frontier, a credit channel influence on economic growth cannot be dismissed.

The fourth hypothesis is that personal income inequality impacts on economic performance. While high levels of inequality have been shown to reduce growth in relatively poor countries but encourage growth in richer countries (Barro 1999), this hypothesis remains controversial (Persson and Tabellini 1994). U.S. states have been shown to exhibit converging income inequality and growth rates (Levernier, Rickman, and Partridge 1995) with a positive relationship between income inequality and future economic growth (Partridge 1997). A lagged effect of income distribution inequality on technical inefficiency is tested here using the 1959 interstate Gini coefficient (GINI59). Income-level inequality is tested using 1969 per capita state income (PC69). As technical efficiency is one way for a state's economy to grow, the test here may be thought of as taking a deeper look at the impact of inequality on one factor causing economic growth. While the 1959 inequality is hypothesized to be growth enhancing (improved economic incentives) based on the literature, the impact of 1969 per capita income levels is uncertain. A positive impact on efficiency by PC69 would suggest that prior efficiency (proxied by a state's per capita income) may lead to future efficiency. However, the positive impact may be more than offset by a negative impact, as states are known to be converging over time.

Some additional control variables are included to account for variables that have been shown in the literature to impact on growth. The variables are to control for the stock of human capital, a possible urban agglomeration effect, and labor markets. Specifically, they are 1980 data on education (percent of the population over 25 years with a high school or college diploma as a terminal degree 
(HSPLUS, COLL)), urban residency (percent of the population in a metropolitan area (METRO)), and employment (percent of nonagricultural employment that is employed in manufacturing, mining, and construction (GOODS) and-here not 1980-percent change in nonagricultural employment 1960-1970 (EGROW)). The impact of these variables a priori on technical inefficiency is uncertain. For example, relatively better education may imply more technical inefficiency if labor is not matched well to the existing capital stock, or higher efficiency as labor markets clear faster. Agglomeration effects measured by METRO may imply lower technical inefficiency as competition improves factor market efficiency. A positive impact of 1960s employment growth on efficiency during 1977-1986 may indicate that a stronger economy in some states will be efficiency enhancing in a future decade when the economy slows, or just the opposite if convergence is occurring. Descriptive statistics on all variables are found in Table 1.

TABLE 1

Descriptive Statistics, U.S. States, 1977-1986

\begin{tabular}{|c|c|c|c|c|}
\hline \\
\hline \multicolumn{5}{|c|}{ Minimum Maximum } \\
\hline Aggregate GSP & $5,007.0$ & $473,357.0$ & $66,496.2$ & $75,401.7$ \\
\hline private sector only & $4,421.0$ & $422,665.0$ & $59,031.5$ & $67,487.2$ \\
\hline public sector only & 586.0 & $50,692.0$ & $7,464.7$ & $8,181.1$ \\
\hline Aggregate Capital Stock & $7,788.9$ & $506,210.7$ & $90,800.8$ & $91,504.1$ \\
\hline private sector only & $4,805.9$ & $375,341.6$ & $64,380.1$ & $65,554.6$ \\
\hline public sector only & $2,923.0$ & $142,431.0$ & $26,420.6$ & $28,654.3$ \\
\hline Aggregate Labor Force & 170.5 & $11,258.1$ & $1,884.0$ & $1,975.2$ \\
\hline private sector only & 132.5 & $9,419.3$ & $1,552.5$ & $1,646.3$ \\
\hline public sector only & 34.3 & $1,838.8$ & 331.5 & 332.9 \\
\hline \multicolumn{5}{|c|}{ b. " $\mathrm{z}$ " Variables Influencing Technical Inefficiency } \\
\hline & Minimum & Maximum & Mean & SD \\
\hline Aggregate GSP & $50,07.0$ & $473,357.0$ & $66,496.2$ & $75,401.7$ \\
\hline Captial Efficiency (KEFF) & -12.7 & 27.1 & 4.30 & 5.64 \\
\hline Labor Efficiency (LEFF) & -2.6 & 11.3 & 1.39 & 2.27 \\
\hline $\begin{array}{l}\text { \% Share of } 1970 \text { Manufacturing } \\
\text { in Nonagricultural Employment } \\
\text { (MANUSH) }\end{array}$ & 4.23 & 40.42 & 25.01 & 9.71 \\
\hline Small Bank Lending (BANK) & 1.2 & 73 & 31.74 & 22.02 \\
\hline $\begin{array}{l}1959 \text { Gini Income Inequality } \\
\text { Coefficient (GINI59) }\end{array}$ & 0.31 & 0.42 & 0.36 & 0.03 \\
\hline Per Capita 1969 Income (PC69) & 2,575 & 4,865 & $3,641.42$ & 553.55 \\
\hline High School Dip. (HSPLUS) & 40.28 & 61.05 & 51.13 & 5.70 \\
\hline College Dip. (COLL) & 10.4 & 23 & 15.90 & 2.87 \\
\hline \% Urban Pop. (METRO) & 18.3 & 100 & 63.27 & 22.58 \\
\hline $\begin{array}{l}\% \text { of } 1980 \text { Nonagricultural } \\
\text { Employment in Manufacturing, } \\
\text { Mining, and Construction (GOOD) }\end{array}$ & 12.80 & 39.71 & 28.20 & 6.20 \\
\hline $\begin{array}{l}\text { \% Change in Nonagricultural } \\
\text { Employment 1960-1970 (E6070) }\end{array}$ & 12.23 & 96.62 & 34.39 & 15.22 \\
\hline
\end{tabular}




\section{METHODOLOGY}

A log linear production function is applied using a maximum likelihood econometric method (Battese and Coelli 1995) that simultaneously incorporates outside, or " $z$," factors that may impact on technical inefficiency over time and space. The separate econometric rankings serve as an independent test of the robustness of LP rankings from earlier work (Domazlicky and Weber 1997, 1998), as the econometric method imposes a functional form and error structure. Since the choice of functional form has been found to influence technical efficiency scores (Harris 1992) and productivity growth estimation (Fogarty and Garofalo 1988), both a standard Cobb-Douglas and a more flexible Variable Elasticity of Substitution (VES) functional form (Bairam 1987) are applied, with the best-fitting form used for calculating technical efficiency scores. Separate private and public sector production functions are applied in addition to an aggregate public/private equation to examine the two sectors individually. Technical efficiency scores for all 48 contiguous states are taken as measures of relative economic performance over the 1977-1986 period.

Other factors thought to influence state economic performance are included in the error structure when simultaneously estimating technical inefficiency in a one-stage procedure. These " $z$ " factors impact on the ability of a state to utilize capital and labor to create GSP. More specifically, the production function is:

$$
\begin{aligned}
& \ln (G S P / L)_{i t}=a+b[t]+c\left[\ln (K / L)_{i t}\right]+h\left[(K / L)_{i t}\right]+v_{i t}-u_{i} e \\
& i=1, \ldots, 48 ; t=1, \ldots, 10,
\end{aligned}
$$

where " $i$ " indexes states and " $t$ " indexes the years 1977-1986. If " $h$ " is insignificant, the production function collapses to the standard Cobb-Douglas form. The composite error term consists of the standard white noise " $v$ " and a second component, " $u$," representing technical inefficiency. The " $v$ " component is assumed to be i.i.d. normal with zero mean and an unknown variance $\left(\sigma_{\mathrm{v}}^{2}\right)$. The distribution of " $u$ " is assumed to be i.i.d. positive truncations of a normal distribution with unknown mean $\left(\mathrm{m}_{\mathrm{i}}\right)$ and variance $\left(\sigma_{\mathrm{u}}^{2}\right)$ :

$$
\mathrm{u}_{\mathrm{i}}=\mathrm{z}_{\mathrm{i}} \mathrm{d}+\mathrm{w}_{\mathrm{i}} \cdot
$$

The mean of " $u$," though unknown, consists of a vector of variables $z_{i}$ (NC, SA, SC, W, D82, KEFF, LEFF, MANUSH, BANK, GINI59, PC69, HSPLUS, COLL, METRO, GOODS, EGROW) that may influence the relative efficiency of a state $\left(m_{i}=d z_{i}\right)$ and a vector of parameters $(d)$ to be estimated. Positive coefficients on $d$ indicate that a $\mathrm{z}$ variable contributes to technical inefficiency. The random variable $\mathrm{w}_{\mathrm{i}}$ has a truncated normal distribution with zero mean and variance $\sigma^{2}$. A state's technical efficiency of production in a given year is defined by: 


$$
T E_{i}=\exp \left(-u_{i}\right)=\exp \left(-z_{i} d-w_{i}\right)
$$

Earlier work usually estimated the influence of $z_{i}$ in a second-stage regression after unit inefficiency scores were estimated to identify why differences in predicted inefficiencies existed. However, the second stage was criticized as being inconsistent in the assumptions about the independence of inefficiency in the two stages. A one-stage procedure was developed in the early 1990 s by placing the inefficiency effects in an explicit function of a vector of state-specific variables and a random error (see Coelli 1994 for a description of this literature and the program to run the one-stage procedure). Technical inefficiency is assumed to be time invariant, as the lack of annual data for some of the " $\mathrm{z}$ " variables that are drawn from a variety of studies does not permit testing for time invariance. ${ }^{1}$

Whether a stochastic frontier approach is superior to OLS can be tested by

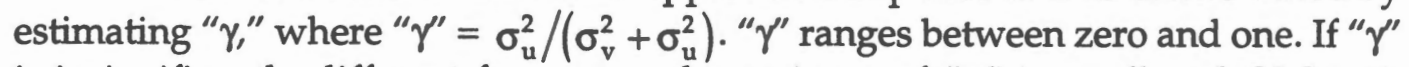
is insignificantly different from zero, the variance of " $u$ " is small and OLS estimates may be sufficient, as technical inefficiency is low. If, on the other hand, " $\gamma$ " is significantly different from zero, $\sigma_{u}^{2}$ is large and a frontier production function is the true model.

\section{RESULTS}

Production function results (Table 2) indicate the usefulness of applying both LP and econometric methods as well as testing for the existence of technical inefficiency. Aggregate and private-sector-only data fit a standard Cobb-Douglas functional form well and were superior to the more general VES form (not shown), suggesting that an assumption of constant returns to scale at this high level of aggregation is reasonable. ${ }^{2}$ However, public-sector-only data did not have meaningful economic estimates with either the Cobb-Douglas or VES functional form, as both yielded a negative coefficient on the capital/labor ratio regressor. The lack of profit-maximizing behavior in the public sector may be yielding the weaker results and could also bias the aggregate results, suggesting that the private sector results are more reliable. Both aggregate and private sector results suggest that additional capital and labor contribute to GSP growth extensively given the positive coefficient on the capital/labor ratio. Technological progress during the 10-year business cycle period was about 0.5 percent for either data set, indicating that the frontier was slowly shifting out.

\footnotetext{
${ }^{1}$ This is clearly an area for further research. Related to this issue is the potential existence of errors in variables if the " $z$ " variables are correlated with each other. Most of the " $z$ " variables are not either positively or negatively highly correlated with each other. The few that are (income positively correlated with college or high school education; small banks lending negatively correlated with urban population; West and South Central regional dummies positively and negatively, respectively, correlated with high school education) do not readily lend themselves to an instrumental variable approach to fixing the problem. For example, eliminating college education because of high correlation (0.62) with 1980 income still leaves a high school education variable strongly related $(0.43)$ to income. Because very few correlations exceed 0.50 , multicollinearity is believed to not be a problem in the regression.

2The VES form tested was Bairam's (1987) adjusted Cobb-Douglas function. The results from those regressions yielded untenable (negative) coefficients on the capital/labor ratio. Further, the adjusted R-squared was not improved significantly by using the VES relative to a standard Cobb-Douglas function.
} 
TABLE 2

Panel Production Function Results, U.S. States, 1977-1986

\begin{tabular}{lccc}
\hline Coefficient & $\begin{array}{c}\text { Aggregate Public } \\
\text { \& Private Sector } \\
\text { (t-stat.) }\end{array}$ & $\begin{array}{c}\text { Private Sector } \\
\text { Only } \\
(t-s t a t .)\end{array}$ & $\begin{array}{c}\text { Public Sector } \\
\text { Only } \\
(t-s t a t .)\end{array}$ \\
\hline Intercept & $2.326^{* *}$ & $2.568^{* *}$ & $3.499^{* *}$ \\
Trend & $(24.079)$ & $(50.225)$ & $(21.308)$ \\
& $0.005^{* *}$ & $0.005^{* *}$ & 0.003 \\
$\log (\mathrm{K} / \mathrm{L})$ & $(10.01)$ & $(3.908)$ & $(1.416)$ \\
& $0.318^{* *}$ & $0.309^{* *}$ & $-0.104^{* *}$ \\
Gamma & $(18.065)$ & $(24.253)$ & $(-2.739)$ \\
& 0.0000007 & $0.0014^{* *}$ & no frontier estimated \\
Likelihood Ratio & $(0.002)$ & $(1.975)$ & \\
test of one-sided error & $485.9^{* *}$ & & \\
\hline
\end{tabular}

"Significant at $1 \%$ level.

* Significant at $5 \%$ level.

The existence of a technical efficiency frontier is confirmed only for the private sector by a gamma coefficient that is low but significantly different from zero, suggesting that OLS is inappropriate with these data. The aggregate results suggest that OLS is appropriate and that states do not differ very much in terms of efficiency, with the caveat that the poorly fitting public sector data may weaken these results. A likelihood-ratio test for a one-sided error term also supports the existence of states off the frontier and supports the earlier work using LP that assumes that some interstate technical inefficiency exists. Similar to LP results, states are found to be bunched near the 100 percent efficient frontier, with few states exhibiting large technical inefficiency at either the aggregate (mean technical efficiency $=93$ percent) or private sector (mean technical efficiency $=87$ percent) level (Table 3). The positive correlation between the LP technical efficiency state rankings and the econometric private sector $(0.62)$ and aggregate $(0.68)$ results supports the idea that what is being measured is indeed interstate technical inefficiency regardless of the method used. Most of the states that receive a 100 percent efficient score using LP, and therefore create the frontier envelope, are the same as the econometric frontier, with a few exceptions (such as Colorado). However, econometric results, which do not subsume measurement error into the technical efficiency scores (unlike the LP method), indicate that states are much more alike and have less "catching up" to do relative to LP results (e.g., Vermont LP $=0.7883$, econometric $=0.81$ ). Indeed, the lack of overall statistically significant inefficiency at the aggregate level suggests that states are all close to being on the best practice efficiency frontier. Whether they have converged to this awaits further analysis of prior periods where the necessary data are not yet available (i.e., aggregate capital stock).

The various influences on technical inefficiency, as measured by the vector of $\mathrm{z}$ variables, revealed that several hypotheses about a state's utilization of resources to create GSP can be rejected at both the aggregate and private-sectoronly levels (Table 4). Given the lack of overall statistically significant inefficiency, the aggregate $\mathrm{z}$ vector results are presented in Table 4 but the following discussion 
focuses on the private sector results. For example, despite significant coefficients for the aggregate results, the lack of evidence for a monetary channel (BANK) or an urban agglomeration (METRO) effect on technical inefficiency in the private sector leads to the conclusion that there is no monetary channel or urban agglomeration effect.

TABLE 3

Technical Efficiency Rankings for U.S. States, 1977-1986

\begin{tabular}{|c|c|c|c|}
\hline \multirow[b]{2}{*}{ State } & \multirow{2}{*}{$\begin{array}{c}\text { LP Method } \\
\text { Public \& Private Sector }\end{array}$} & \multicolumn{2}{|c|}{ Econometric Method } \\
\hline & & Public \& Private Sector & Private Sector Only \\
\hline$\overline{\mathrm{AL}}$ & 0.8175 & 0.92 & 0.830 \\
\hline $\mathrm{AZ}$ & 0.8999 & 0.95 & 0.850 \\
\hline $\mathrm{AR}$ & 0.8185 & 0.87 & 0.790 \\
\hline CA & 1.0000 & 1.00 & 0.970 \\
\hline $\mathrm{CO}$ & 0.9279 & 1.00 & 0.940 \\
\hline $\mathrm{CT}$ & 1.0000 & 1.00 & 0.980 \\
\hline $\mathrm{DE}$ & 0.8543 & 0.95 & 0.860 \\
\hline FL & 0.9014 & 0.87 & 0.770 \\
\hline GA & 0.8621 & 0.87 & 0.770 \\
\hline ID & 0.8212 & 0.84 & 0.800 \\
\hline IL & 0.9460 & 1.00 & 0.970 \\
\hline IN & 0.8646 & 0.90 & 0.820 \\
\hline IA & 0.8520 & 0.87 & 0.820 \\
\hline KS & 0.8376 & 0.96 & 0.910 \\
\hline $\mathrm{KY}$ & 0.8845 & 0.95 & 0.870 \\
\hline LA & 1.0000 & 1.00 & 0.950 \\
\hline MA & $n / a$ & 0.84 & 0.780 \\
\hline ME & 0.8116 & 0.98 & 0.900 \\
\hline MD & 0.9999 & 0.96 & 0.900 \\
\hline MI & 0.9190 & 0.94 & 0.870 \\
\hline $\mathrm{MN}$ & 0.8458 & 0.92 & 0.850 \\
\hline MS & 0.8104 & 0.85 & 0.770 \\
\hline MO & 0.8830 & 0.92 & 0.860 \\
\hline MT & 0.8574 & 0.89 & 0.860 \\
\hline NE & 0.8233 & 0.88 & 0.830 \\
\hline NV & 0.9995 & 0.95 & 0.850 \\
\hline $\mathrm{NH}$ & 0.9263 & 0.88 & 0.810 \\
\hline NJ & 1.0000 & 1.00 & 0.940 \\
\hline NM & 1.0000 & 0.99 & 0.930 \\
\hline NY & 0.9790 & 1.00 & 0.996 \\
\hline $\mathrm{NC}$ & 0.9635 & 0.86 & 0.760 \\
\hline ND & 0.8249 & 0.92 & 0.870 \\
\hline $\mathrm{OH}$ & 0.8965 & 0.94 & 0.870 \\
\hline OK & 0.9730 & 0.99 & 0.920 \\
\hline OR & 0.8263 & 0.91 & 0.840 \\
\hline PA & 0.8528 & 0.91 & 0.850 \\
\hline RI & 1.0000 & 1.00 & 0.930 \\
\hline SC & 0.9043 & 0.84 & 0.740 \\
\hline SD & 0.7989 & 0.85 & 0.830 \\
\hline TN & 0.8304 & 0.92 & 0.830 \\
\hline TX & 1.0000 & 1.00 & 0.980 \\
\hline UT & 0.8683 & 0.95 & 0.870 \\
\hline VT & 0.7883 & 0.87 & 0.810 \\
\hline VA & 1.0000 & 0.96 & 0.860 \\
\hline WA & 0.9818 & 0.97 & 0.900 \\
\hline WV & 0.7912 & 0.91 & 0.840 \\
\hline WI & 0.8659 & 0.92 & 0.840 \\
\hline WY & 1.0000 & 1.00 & 1.000 \\
\hline MEAN & 0.9000 & 0.93 & 0.870 \\
\hline
\end{tabular}




\section{TABLE 4}

" $z$ " Variables Influencing Technical Inefficiency

\begin{tabular}{|c|c|c|}
\hline Coefficient & $\begin{array}{l}\text { Public \& Private Sector } \\
\text { (t-stat.) }\end{array}$ & $\begin{array}{l}\text { Private Sector Only } \\
\text { (t-stat.) }\end{array}$ \\
\hline Capital Efficiency & $\begin{array}{l}0.0002 \\
(0.2)\end{array}$ & $\begin{array}{l}0.00002 \\
(0.022)\end{array}$ \\
\hline Labor Efficiency & $\begin{array}{l}-0.0024^{* *} \\
(-1.821)\end{array}$ & $\begin{array}{l}-0.0027^{*} \\
(-1.55)\end{array}$ \\
\hline North Central Dummy & $\begin{array}{l}-0.053^{* *} \\
(-3.287)\end{array}$ & $\begin{array}{l}-0.052^{* *} \\
(-3.991)\end{array}$ \\
\hline South Atlantic Dummy & $\begin{array}{r}0.0007 \\
(0.016)\end{array}$ & $\begin{array}{c}0.016 \\
(1.071)\end{array}$ \\
\hline South Central Dummy & $\begin{array}{r}-0.097^{*} \\
(-1.612)\end{array}$ & $\begin{array}{l}-0.099^{* *} \\
(-5.305)\end{array}$ \\
\hline West Dummy & $\begin{array}{l}-0.083^{* *} \\
(-8.858)\end{array}$ & $\begin{array}{l}-0.073^{* *} \\
(-5.264)\end{array}$ \\
\hline 1982 Dummy (=1 in 1982 only) & $\begin{array}{l}0.035^{* *} \\
(3.465)\end{array}$ & $\begin{array}{r}0.04^{* *} \\
(4.281)\end{array}$ \\
\hline $\begin{array}{l}\text { \% Share of } 1970 \text { Manufacturing in } \\
\text { Nonagricultural Employment }\end{array}$ & $\begin{array}{l}0.009^{* *} \\
(18.241)\end{array}$ & $\begin{array}{l}0.0096^{* *} \\
(12.903)\end{array}$ \\
\hline Share of Lending from Small Banks & $\begin{array}{l}-0.0004^{* *} \\
(-1.909)\end{array}$ & $\begin{array}{l}-0.0001 \\
(-0.416)\end{array}$ \\
\hline $\begin{array}{l}1959 \text { Gini Income Inequality } \\
\text { Coefficient }\end{array}$ & $\begin{array}{l}0.567^{* *} \\
(2.985)\end{array}$ & $\begin{array}{l}0.575^{* *} \\
(5.803)\end{array}$ \\
\hline Per Capita Personal 1969 Income & $\begin{array}{l}-0.0001^{* *} \\
(-13.256)\end{array}$ & $\begin{array}{l}-0.00012^{* *} \\
(-12.63)\end{array}$ \\
\hline $\begin{array}{l}\text { \% of } 1980 \text { Population Over } 25 \\
\text { with a College Diploma }\end{array}$ & $\begin{array}{l}-0.0054^{*} \\
(-1.36)\end{array}$ & $\begin{array}{l}-0.005^{* *} \\
(-3.035)\end{array}$ \\
\hline $\begin{array}{l}\text { \% of } 1980 \text { Population Over } 25 \\
\text { with a High School Diploma }\end{array}$ & $\begin{array}{r}0.01^{* *} \\
(5.014)\end{array}$ & $\begin{array}{l}0.0098^{* *} \\
(10.479)\end{array}$ \\
\hline $\begin{array}{l}\% \text { of } 1980 \text { Population in a } \\
\text { Metropolitan Area }\end{array}$ & $\begin{array}{l}-0.0008^{* *} \\
(-4.102)\end{array}$ & $\begin{array}{l}-0.0003 \\
(-1.359)\end{array}$ \\
\hline $\begin{array}{l}\text { \% of } 1980 \text { Nonagricultural } \\
\text { Employment in Manufacturing, } \\
\text { Mining, and Construction }\end{array}$ & $\begin{array}{l}-0.012^{* *} \\
(-5.112)\end{array}$ & $\begin{array}{l}-0.0098^{* *} \\
(-11.377)\end{array}$ \\
\hline $\begin{array}{l}\text { \% Change in Nonagricultural } \\
\text { Employment 1960-1970 }\end{array}$ & $\begin{array}{c}0.001 \\
(1.268)\end{array}$ & $\begin{array}{l}0.002^{* *} \\
(7.698)\end{array}$ \\
\hline
\end{tabular}

*"Significant at 1\% level.

* Significant at 5\% level.

Geography influences technical inefficiency but there is no "snowbelt" effect. North Central, South Central, and West regions exhibit higher technical efficiency than the North East region. Why this is so is an area for further research. Also, the 1982 recession dummy suggests that short-term recessions alone can increase inefficiency, even with concurrent positive technological progress during the 10-year business cycle. During a given business cycle, increased unemployment of both labor and capital in a given year leads to states being farther away from a best practice frontier than in other years.

Prior Hicks augmenting growth in the manufacturing capital stock (KEFF) has no influence on technical efficiency but manufacturing labor augmenting growth (LEFF) does. Further support for a human capital impact is found, with college education improving technical efficiency while high school education alone increasing inefficiency. The policy implication here is that state support for programs such as Georgia's Hope Scholarships, which might increase college 
enrollments and potentially graduation rates, will positively improve a state's future economic growth. Programs that improve GED completion may not help with future efficiency.

States with a relatively high degree of manufacturing in 1970 (MANUSH) are less efficient in the 1977-1986 business cycle. Further, states that had relatively high employment growth in the 1960s (EGROW) were less efficient during the 1977-1986 period as well. However, states with a relatively high 1980 percentage of nonagricultural employment in manufacturing, mining, and construction (GOODS) were more efficient. These results suggest that 1960s growth, especially manufacturing growth, would not improve a state's performance in the future. States ten years later are more efficient, with a higher manufacturing share probably due to structural changes in their manufacturing sectors or a growing service economy (which helps a state grow but is also relatively inefficient compared to manufacturing). Growth in one decade does not ensure high efficiency in a future decade.

Income inequality strongly influences technical efficiency. In support of the Persson and Tabellini (1994) hypothesis, 1959 income inequality (GINI59) leads to lower future technical efficiency. The idea that income inequality acts as an economic incentive to improve the future efficient use of resources in a state is not supported. However, 1969 per capita income (PC69) positively impacts on future technical efficiency, suggesting that the level of income positively influences future efficiency. Such apparent mixed results can be explained by the idea that there has been interstate convergence over time, plus there may be historically wealthier states with high efficiency not related to income inequality within the state.

\section{CONCLUSIONS}

Applying a new method to U.S. state data, technical inefficiency in the 48 contiguous U.S. states in the period 1977-1986 is found to be low but significant for the private sector only, with states much alike at the aggregate public/private level. Compared to earlier work, states have less catching up to do and do not exhibit technological regress. The consideration of the public sector in addition to the private sector appears to dampen technical efficiency differences across states. However, public sector data alone do not fit a standard production function well, making public/private aggregate results less reliable.

Less efficient states can do more to better utilize their existing resources relative to more efficient states. Qualitative improvements in manufacturing labor and programs to improve college graduation will improve resource utilization in a state, while the mere presence of manufacturing is not important. States cannot rest on past growth experience, as growth in one decade does not necessarily imply better efficiency in a future decade. While wide income disparities in any state should be a cause of social concern, evidence here suggests that inequality may be producing anti-efficiency policies that do not allow, for example, those 
who accumulate human capital to privately keep the fruit of their labor. Policies should be changed to both promote human capital accumulation and allow those who do so to keep the returns from it.

\section{REFERENCES}

Bairam, E. "Soviet Postwar Industrial Growth and Capital Labour Substitution." Economics Letters 24 (1987), 331-334.

Barro, R. "Inequality, Growth and Investment." NBER Working Paper No. 7038. Cambridge, MA: National Bureau of Economic Research, 1999.

Battese, G.E., and T. Coelli. "A Model for Technical Inefficiency Effects in a Stochastic Frontier Production Function for Panel Data." Empirical Economics 20 (1995), 325-332.

Carlino, G., and R. DeFina. "The Differential Regional Effects of Monetary Policy: Evidence from the U.S. States." Federal Reserve Bank of Philadelphia Working Paper No. 97-12/R, 1998.

Coelli, T. "A Guide to FRONTIER Version 4.1: A Computer Program for Stochastic Frontier Production and Cost Function Estimation." Working Paper, Department of Econometrics, Armidale, Australia, 1994.

Crain, W.M., and K.J. Lee. "Economic Growth Regressions for the American States: A Sensitivity Analysis." Economic Inquiry 37 (2) (1999), 242-257.

Domazlicky, B.R., and W.L.Weber. "Total Factor Productivity in the Contiguous United States, 1977-86." Journal of Regional Science 37 (2) (1997), 213-233.

. "Determinants of Total Factor Productivity, Technological Change, and Efficiency Differentials Among States, 1977-86." The Review of Regional Studies 28 (2) (1998), 19-33.

"Total Factor Productivity Growth in Manufacturing: A Regional Approach Using Linear Programming." Regional Science and Urban Economics 29 (1999), 105-122.

Fogarty, M.S., and G.A. Garofalo. "Urban Spatial Structure and Productivity Growth in the Manufacturing Sector of Cities." Journal of Urban Economics 23 (1988), 60-70.

Forsund, F., C.A.K. Lovell, and P. Schmidt. "A Survey of Frontier Production Functions and of Their Relationship to Efficiency Measurement." Journal of Econometrics 13 (1980), 5-25.

Fried, H.O., C.A. Knox Lovell, and S.S. Schmidt, eds. The Measurement of Productive Efficiency. New York: Oxford University Press, 1993.

Gerking, S. "Measuring Productivity Growth in U.S. Regions: A Survey." International Regional Science Review 16 (1\&2) (1994), 155-185.

Harris, C.M. "Technical Efficiency in Australia: Phase I." In R. Caves and Associates (eds.) Industrial Efficiency in Six Nations. Cambridge, MA: MIT Press, 1992.

Holtz-Eakin, D. "State Specific Estimates of State and Local Government Capital." Regional Science and Urban Economics 23 (1993), 185-209. 
Kashyap, A.K., and J.C. Stein. "The Impact of Monetary Policy on Bank Balance Sheets." NBER Working Paper No. 4821. Cambridge, MA: National Bureau of Economic Research, 1994.

Krugman, P. "Increasing Returns and Economic Geography." Journal of Political Economy 99 (1991), 483-499.

Levernier, W., D.S. Rickman, and M.D. Partridge. "Variation in U.S. State Income Inequality, 1960-90." International Regional Science Review 18 (3) (1995), 355-378.

Levine, R., and S. Zervos. "Stock Markets, Banks, and Economic Growth." American Economic Review 88 (3) (June 1998), 537-558.

Munnell, A. "How Does Infrastructure Affect Regional Economic Performance?" In A. Munnell (ed.) Is There a Shortfall in Public Capital Investment? 69-103. Boston: Federal Reserve Bank of Boston, 1990.

Partridge, M.D. "Is Inequality Harmful for Growth? Comment." American Economic Review 87 (5) (December 1997), 1019-1032.

Persson, T., and G. Tabellini. "Is Inequality Harmful for Growth?" American Economic Review 84 (3) (June 1994), 600-621.

Williams, M., and R.L. Moomaw. "Capitol and Labour Efficiencies: A Regional Analysis." Urban Studies 26 (1989), 573-585. 
